\title{
InterAção no núcleo da promoção de sexualidades saudáveis: competência para a ação e uso de tecnologias de informação e comunicação na escola ${ }^{1}$
}

\begin{abstract}
Resumo
O objetivo deste estudo é analisar como é que os/as alunos/as selecionam os problemas relacionados com a sexualidade para desenvolverem a sua competência para a ação, num projeto de educação em sexualidade democrática, dialógica e emancipatória baseado na metodologia IVAM, com a utilização das TIC. Este estudo de caso envolveu alunos de quatro turmas do $8^{\circ}$ ano $(\mathrm{N}=92)$, com uma média de idades de 13.8 anos $(13-17$ anos, DP $=.46)$. Os dados recolhidos através de observação e dos documentos publicados pelos/as alunos/as no Website do projeto foram analisados num sistema de categorias indutivo. Os/as alunos/as selecionaram os problemas a partir da discussão sobre o que é a sexualidade e da sua escolha autónoma de uma estratégia para investigar as manifestações da sexualidade, entre as várias alternativas sugeridas pelas docentes. Como resultado da análise crítica de telenovelas de diferentes épocas, identificaram como problemas que queriam ajudar a resolver com os seus projetos orientados para ação os seguintes: i) a dificuldade dos/as amigos/as e da família analisarem criticamente os aspetos negativos da influência da TV na sexualidade das pessoas; ii) os colegas não valorizarem uma visão dinâmica e não estática da sua autoimagem; iii) existirem estereótipos de género que prejudicam as pessoas; ii) falta de competências para terem comunicações assertivas quando namoram; iv) prevenção da gravidez não planeada; v) prevenção das infeções sexualmente transmissíveis.
\end{abstract}

Palavras-chave: Educação em Sexualidade; Competência para a Ação; Metodologia IVAM; Tecnologias de Informação e Comunicação.

\section{Para citar este artigo:}

VILAÇA, Teresa. InterAção no núcleo da promoção de sexualidades saudáveis: competência para a ação e uso de tecnologias de informação e comunicação na escola. Revista Linhas. Florianópolis, v. 17, n. 34, p. 2857, maio/ago. 2016.

\footnotetext{
* Optou-se por manter a grafia da língua nativa (Língua Portuguesa - Portugal).

${ }^{1}$ Agradecimentos: Este trabalho foi financiado pela Fundação para a Ciência e Tecnologia (FCT) no âmbito da Bolsa de Investigação em países estrangeiros SFRH/BSAB/113780/2015 e por Fundos Nacionais através da FCT e cofinanciado pelo Fundo Europeu de Desenvolvimento Regional (FEDER) através do COMPETE 2020 Programa Operacional Competitividade e Internacionalização (POCI) no âmbito do CIEC (Centro de Investigação em Estudos da Criança da Universidade do Minho) com a referência POCl-01-0145-FEDER007562.
} 


\title{
InterAction at the core of the promotion of healthy sexuality: action competence and the use of information and communication technologies in school
}

\begin{abstract}
This study aims to analyse how students select problems related to sexuality in order to develop their action-competence, in a democratic, dialogical and emancipatory sexuality education project, based on the IVAC methodology with the use of ICT. This case study involved students of four 8 th grade classes $(\mathrm{N}=$ 92), with an average age of 13.8 years (13-17 years, $S D=$ .46). Data collected through observation and documents published by the students in the project Website were analysed applying a inductive category system. Students selected the problems from the discussion regarding what sexuality is and of their autonomous selection of a strategy to investigate the manifestations of sexuality, among the various alternatives suggested by teachers. As a result of the critical analysis regarding soap operas of different eras, these students identified the following problems they wanted to solve in their action-oriented projects: i) the difficulty of their friends and family to critically analyse the negative aspects of the influence of TV on the sexuality of people; ii) the fact that their colleagues do not value a dynamic and non static view of their self-image; iii) the gender stereotypes that harm people; ii) the lack of skills necessary in assertive communication when dating; iv) prevention of unplanned pregnancy; v) prevention of sexually transmitted infections.
\end{abstract}

Keywords: Sexuality Education; Action Competence; IVAC Methodology; Information and Communication Technologies. 


\section{Introdução}

No debate pedagógico relacionado com a educação em sexualidade é, muitas vezes, enfatizado que o ensino deve ser feito através do uso de estratégias ativas (VILAÇA, 2008a) e do desenvolvimento de ações pelos/as alunos/as que contribuam para eliminar as causas que determinam as condições de saúde negativas, incluindo a ausência de bem-estar (ex., JENSEN, 2000; SIMOVSKA, 2005) e, mais especificamente, as causas que determinam a sua saúde sexual ${ }^{2}$ ou a da comunidade em que estão inseridos/as (ex., VILAÇA, 2008b, 2012, 2014; VILAÇA; SEQUEIRA; JENSEN, 2011). Neste sentido, atualmente há uma forte tendência para centrar a investigação da educação em sexualidade democrática e emancipatória nos aspetos metodológicos, sendo uma questão central para o/a investigador/a ser capaz de tornar o ensino mais eficaz e desenvolver novos métodos que alcancem o objetivo de desenvolver nos/as alunos/as a sua capacidade para agirem reflexivamente, individual e/ou coletivamente, no sentido de resolverem os seus próprios problemas e promoverem o seu bem-estar sexual, bem como os da sua comunidade, isto é, desenvolverem a sua competência para a ação.

Capacitar as crianças, adolescentes, jovens e adultos para a eliminação das causas multidisciplinares que originam os problemas de saúde sexual atuais, relacionados com o género, diversidade sexual, sexualidade em pessoas com deficiência, diversidade cultural e religiosa e, também, prevenção da gravidez não planeada e das infeções sexualmente transmissíveis ou da violência no namoro ou doméstica, é um grande desafio para o ambiente educacional. Se o objetivo do ensino é desenvolver as possíveis soluções para esses problemas, é necessária uma ruptura fundamental com as formas atuais de pensar na saúde sexual e na educação em sexualidade. No mundo da educação, isso significa compreender se os problemas que constituem os conteúdos centrais da aprendizagem devem ter uma posição mais central do que os problemas de natureza metodológica.

Um argumento importante para defender a centralidade da metodologia da educação em detrimento do conteúdo dos problemas tratados quando o objetivo é o

\footnotetext{
${ }^{2}$ A saúde sexual é entendida neste capítulo numa perspectiva holística que inclui "a integração dos aspectos somáticos, emocionais, intelectuais e sociais do ser sexual, de maneira que sejam positivamente enriquecedores e engrandeçam a personalidade, a comunicação e o amor" (WORLD HEALTH ORGANIZATION, 1975, p.2), o que implica que a sexualidade é experienciada e expressa em pensamentos, fantasias, desejos, crenças, atitudes, valores, comportamentos, práticas, papéis e relações (WORLD HEALTH ORGANIZATION, 2000).
} 
desenvolvimento da competência para a ação dos/as participantes, é que a educação em sexualidade tem que lidar com um contexto interdisciplinar orientado para a resolução de problemas de saúde sexual específicos. Assim, neste capítulo defende-se que a educação em sexualidade deve basear-se num ensino orientado para a ação, desenvolvido dentro de uma perspetiva democrática, dialógica e emancipatória, envolvendo o trabalho com uma ampla área do conhecimento (biológico, psicológico e social), não só sobre as consequências e causas dos problemas de saúde sexual mas, também, sobre as estratégias a desenvolver para eliminar essas causas e atingir as visões que temos para o futuro. Por outras palavras, o conhecimento orientado para a ação é um conhecimento interdisciplinar complexo, construído num processo compartilhado de diálogo crítico, reflexão, desenvolvimento de visões, planejamento e ação como parte dos processos de ensino e aprendizagem (SIMOVSKA; JENSEN, 2003; VILAÇA, 2012, 2014; VILAÇA; SEQUEIRA; JENSEN, 2011).

\section{Referêncial teórico Ação e competência para a ação}

Ação versus atividade e comportamento. Uma ação é uma atividade decidida pelos/as participantes (não pelo/a professor/a) e dirigida para a solução do problema em questão (JENSEN, 1994; 1995; JENSEN; NIELSEN, 1996; JENSEN; SCHNACK, 1994; SIMOVSKA; JENSEN, 2003; VILAÇA; JENSEN, 2009), por isso, é obrigatoriamente uma atividade orientada para a eliminação das causas do problema (JENSEN, 1994; 1997; JENSEN; NIELSEN, 1996). Por exemplo, para se prevenir a violência no namoro não é prioritário desenvolver estratégias para apoiar a vítima a melhorar o rendimento escolar que começou a baixar, a diminuir o seu deficit de atenção nas aulas, a deixar de consumir drogas ou álcool em excesso ou a deixar de se envolver em combates físicos, pois estamos a agir sobre algumas das consequências mais frequentes da violência no namoro. Isto é, não devemos tentar eliminar os sintomas do problema, devemos sim, como prioridade, agir para eliminar as causas da violência, o que implica desenvolver competências na vítima, e em todas as pessoas, para que haja respeito mútuo nas relações de namoro, decisões partilhadas, compreender que os ciúmes excessivos não são uma demonstração de amor, clarificar a falsa ideia de que a vítima é a causadora da 
violência, trabalhar a assertividade para ser capaz de recusar ter relações sexuais quando não o deseja, mesmo que o/a companheiro/companheira pressione, aprender a identificar as diferentes formas de violência no namoro, entre outras.

No ensino orientado para a ação, o objetivo é que os/as alunos/as - com aproximadamente todos os meios disponíveis - possam mudar o seu comportamento numa direção previamente determinada (JENSEN; NIELSEN, 1996; JENSEN; SCHNACK, 1994). Essa é precisamente a componente mais profunda do conceito de ação e que o torna diferente do conceito de mudança de comportamento (JENSEN, 1994; SIMOVSKA; JENSEN, 2003). Antes de uma ação, tem que haver uma tomada de decisão consciente, o que não é necessário no caso da mudança de comportamento. Isto é uma dimensão democrática muito importante na educação para a saúde (JENSEN, 1994; JENSEN; NIELSEN, 1996) e, mais especificamente na educação em sexualidade emancipatória (VILAÇA, 2014). A mudança de comportamento poderá ser causada pela pressão de outra pessoa (ex., o/a professor/a ou colegas) ou por outras circunstâncias como a publicidade, estando a pessoa a seguir só as tendências (orientações) recebidas sem estar consciente das suas ações.

Ações individuais e coletivas. As ações individuais estão muitas vezes associadas aos estilos de vida, enquanto as ações dirigidas para as mudanças das condições de vida são muitas vezes coletivas (JENSEN, 1994; SIMOVSKA; JENSEN, 2003; VILAÇA; JENSEN, 2010). Podem existir quatro categorias para a ação (JENSEN, 1994): ações individuais e coletivas relacionadas com o estilo de vida; e ações individuais e coletivas relacionadas com as condições de vida. O limite entre as ações individuais e coletivas é confuso, mas para qualificar como ações coletivas, os indivíduos que agem têm que ter uma compreensão comum e um objetivo comum para as suas ações. A relevância destes quatro tipos de possibilidade de ação poderá diferir dependendo dos tópicos de ensino em foco. Apesar de tudo, independentemente do tema, o ensino deverá lidar com as quatro categorias, e os resultados potenciais e as barreiras possíveis em cada uma delas deverão ser discutidos como parte dos processos de ensino e de aprendizagem (JENSEN, 1994; SIMOVSKA; JENSEN, 2003). 


\section{Educação em sexualidade democrática, dialógica e emancipatória}

Conhecimento orientado para a ação. Esta abordagem da educação em sexualidade democrática, assente em estratégias que visam a melhoria da comunicação e a criação de relações dialógicas que visem a valorização dos/as participantes através da criação de ambientes comunicativos emancipatórios e transformadores da realidade, é construída sobre um conceito positivo e amplo de saúde sexual, que engloba a prevenção de doenças e a promoção da saúde sexual a partir do "empowerment" (empoderamento) dos indivíduos para controlarem quer os seus estilos de vida quer as suas condições de vida.

Os métodos interdisciplinares são uma condição prévia para o exercício da docência orientada para a ação. Com base na experiência dentro das escolas promotoras de saúde e da educação ambiental, Jensen (1994), um investigador dinamarquês, identificou as seguintes oito perspetivas que devem ser trabalhadas nos projetos de educação para a saúde orientada para ação, e que têm vindo a ser aplicadas com sucesso na rede europeia de escolas para a saúde na europa (SHE, 2009) e na educação em sexualidade democrática, dialógica e emancipatória por Vilaça em Portugal (ex., VILAÇA 2012, 2014; VILAÇA; JENSEN, 2010; VILAÇA; SEQUEIRA; JENSEN, 2011): 1) que assunto deve ser trabalhado; 2) que problema dentro do assunto em questão deve ser trabalhado; 3) quais são as causas deste problema; 4) por que é que se tornou um problema; 5) que alternativas se podem imaginar para o futuro em relação a esse problema; 6) quais são os planos de ação que existem para atingir essas alternativas; 7) quais são as barreiras que poderão surgir e impedir que as ações resultem nas mudanças desejadas e como poderão ser ultrapassadas essas barreiras; e 8) que ações serão iniciadas.

Estas perspetivas não representam necessariamente passos que devem ser trabalhados ou seguidos por uma certa ordem, mas questões que devem ser tratadas durante o processo de aprendizagem (JENSEN, 1994). É importante entender como é que os/as professores/as e os/as alunos/as podem organizar a construção das quatro dimensões do conhecimento acima mencionadas (Que tipo de problema é?; Por que temos os problemas que temos?; Como podemos mudar as coisas ?; Para onde vamos?), a fim de agirem e participarem na resolução dos problemas com os quais podem desenvolver a sua competência para a ação (JENSEN, 2000). 
Metodologia IVAM. A metodologia IVAM (Seleção do problema - Investigação, Visão, Ação e Mudança) foi desenvolvida por Jensen (2000) como um instrumento metodológico prático que pode ser utilizado nas escolas a fim de estruturar as atividades de promoção da saúde e tornar a participação dos/as alunos/as mais fácil, com o objetivo de construir o seu próprio conhecimento orientado para a ação (investigação sobre as consequências e causas do problema e estratégias para a eliminar essas causas) e promover a criação de visões e a implementação de ações para desenvolver a sua competência para a ação.

Este instrumento assume uma série de perspetivas descritas por Jensen (JENSEN, 1997; SIMOVSKA; JENSEN, 2003; VILAÇA; JENSEN, 2009) que podem ser tratadas numa metodologia de projeto baseado na resolução de problemas reais (Figura 1).

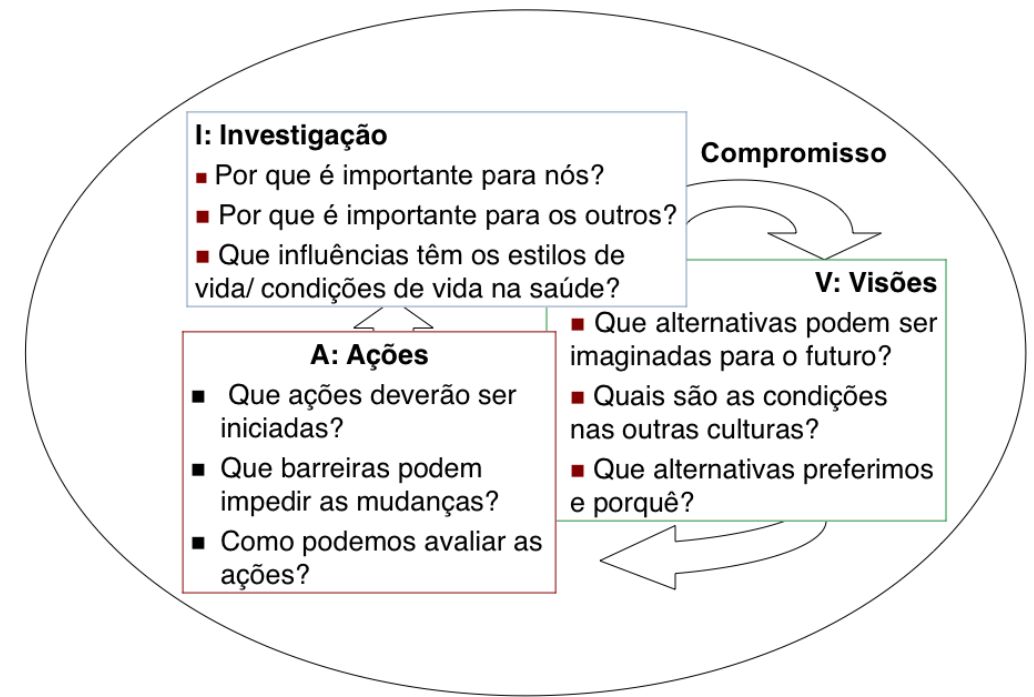

Figura 1: Metodologia IVAM: perspetivas a trabalhar dentro dos projetos de educação em sexualidade orientados para a ação.

Fonte: VILAÇA, 2012, p. 98.

Com esta metodologia é possível esclarecer que tipo de insights e conhecimentos os/as professores/as e os materiais de ensino deverão proporcionar. Dado que o conhecimento entre as pessoas integra elementos científicos, sociais e históricos e os/as alunos/as atingem melhor esses conhecimentos se lhes for permitido ganhar experiência por conta própria, ao resolverem o problema com que estão a trabalhar no projeto, o papel do/a professor/a consiste, em grande medida, em ser um/a consultor/a nos projetos 
orientados para a ação dos/as alunos/as, em vez de apenas os/as sobrecarregar com a aprendizagem de factos científicos pesados.

Na fase de investigação (I) da metodologia IVAM, que deverá ser planeada pelos/as alunos/as com a colaboração do/a professor/a, o material pedagógico ou fontes informativas disponíveis devem criar condições para que os/as participantes investiguem e reflitam criticamente sobre as razões por que o tema ou problema que selecionaram é importante para eles/as e para os/as outros/as, no presente e no futuro. Esta reflexão será conseguida se primeiro os/as alunos/as investigarem as consequências (biológicas, psicológicas e sociais) do problema. O aumento do conhecimento sobre as consequências do problema é uma pré-condição para o desejo de agir, porque esta área de conhecimento faz com que seja possível analisar a gravidade do problema em estudo. Esta análise pode incluir as consequências de certo comportamento, como o não-uso do preservativo ou da pílula anticoncepcional, de uma atitude, como deixar o/a namorado/a chamar-lhe nomes e/ou gritar ou humilhá-lo/a através de críticas negativas, ou as consequências das condições de vida que temos, tais como não ter preservativos ou a pílula facilmente acessíveis ou falta de grupos de suporte a quem recorrer em caso de violência.

Este conhecimento sobre as consequências do problema é importante porque é a área de conhecimento que desperta a nossa atenção e preocupação e, consequentemente, cria um ponto de partida para sentir o desejo de agir. Neste sentido, o conhecimento sobre as consequências pode ser um dos pré-requisitos para o desenvolvimento de capacitação e da competência para a ação dos/as alunos/as. No entanto, é importante alertar para o facto de que se os/as alunos/as apenas constroem esta área de conhecimento (consequências do problema) e não recebem qualquer explicação sobre as razões pelas quais esses problemas existem (causas do problema) e como podemos contribuir para resolvê-los (estratégias de mudança), corremos o risco de contribuir simultaneamente para o despertar do interesse pelo problema e para a paralisia dos/as alunos/as para a ação (JENSEN, 2000; SIMOVSKA; JENSEN, 2003; VILAÇA; JENSEN, 2009).

Deste modo, a segunda área da fase de investigação é pesquisar as causas do problema, que devem ser identificadas o mais cedo possível (JENSEN, 1994). Tais causas, 
o que significa os fatores que determinam a nossa saúde sexual, incluem causas associadas a fatores sociais e psicológicos e podem incluir questões como: Quais os aspetos das nossas condições de vida que influenciam o uso de preservativos?; Por que é mais comum as adolescentes portugueses mais velhas tomarem a pílula mais frequentemente?; Que aspetos das nossas condições de vida nos influenciam para transformar o uso normal de álcool num abuso? (SIMOVSKA; JENSEN, 2003); Por que é comum as vítimas de violência no namoro acreditarem que são as causadoras da violência, acreditarem que não podem recusar ter relações sexuais quando o/a namorado/a quer, acreditarem que uma bofetada ou um insulto não é violência ou que é melhor estar numa relação violenta do que estar sozinha? Mesmo que o problema seja exibido numa sala de aula ou na escola, as causas são muitas vezes encontradas fora desses lugares. Consequentemente, são essenciais os métodos de observação social, onde a saúde e os problemas do ambiente social mostram as estruturas económicas, sociais e culturais em que se desenvolvem os problemas (JENSEN, 1994). Normalmente, este conhecimento sobre as consequências e causas capacita-nos para considerar afirmações como: se eu fizer isto, aquilo vai acontecer ou se estas são as condições ou circunstâncias, os riscos podem aumentar (SIMOVSKA; JENSEN, 2003).

A terceira área do conhecimento a ser investigado é o conhecimento sobre as estratégias de mudança. Este conhecimento é importante porque inclui o conhecimento sobre como ganhar controlo sobre a nossa própria vida, como influenciar o ambiente escolar ou como contribuir para mudar as nossas condições de vida em sociedade (JENSEN, 2000; SIMOVSKA; JENSEN, 2003; VILAÇA; JENSEN, 2009). Esta área de conhecimento é crucial para os projetos de educação em sexualidade orientados para a ação dentro da escola promotora de saúde, e está particularmente relacionada com o campo da psicologia e da sociologia.

$\mathrm{Na}$ segunda fase da metodologia IVAM, visões (V), deve ser desenvolvido o conhecimento sobre alternativas ou visões para o futuro (objetivos visionários), a fim de lidar com o desenvolvimento de ideias, sonhos e percepções dos/as alunos/as em relação à sua vida futura e à sociedade em que desejam crescer (JENSEN, 1994; VILAÇA, 2014; VILAÇA; JENSEN, 2010). 
Na terceira fase da metodologia IVAM, ação e mudança (AM) as mudanças são alcançadas através das ações desenvolvidas para eliminar as causas do problema, isto é, a mudança nos estilos de vida (comportamentos, atitudes, crenças e valores) e nas condições de vida são conseguidas com a realização das ações.

Integração das tecnologias de informação e comunicação na metodologia IVAM. As tecnologias de informação e comunicação (TIC) agilizaram a comunicação por meio da digitalização e da comunicação em redes para a captação, transmissão e distribuição das informações que podem assumir a forma de texto, imagem estática, vídeo ou som através do uso de ferramentas multimédia de fácil acesso, tais como projeção de vídeos educativos ou de imagens em PowerPoint, elaboração de trabalhos em PowerPoint, resolução de fichas formativas digitais, realização de documentários ou pesquisas na Internet pelos/as alunos/as, entrega de trabalhos utilizando o email, criação e dinamização do blogue da disciplina (MARTINHO, 2008), uso de chats, fóruns, e-diários ou publicação das pesquisas dos/as alunos/as em sítios da Web ("websites") (VILAÇA, 2008b). Neste sentido, as TIC aumentam a capacidade de comunicação científica, porque facilitam o uso de uma variedade de formas para representar e comunicar as evidências, ideias e explicações usando uma linguagem científica, nomeadamente através do tratamento de dados (tabelas, gráficos, esquemas, figuras ou diagramas) incluindo usar modelos e divulgar o conhecimento científico através da linguagem escrita (publicação de relatórios, discussões em fóruns) ou oral (Chats, telemóvel, entre outros) (AUSTRALIA, DEPARTMENT OF EDUCATION, 2010).

O sucesso de longo prazo da estratégia de e-Skills da União Europeia requer o envolvimento de todos/as os/as intervenientes no diálogo e parcerias para a ação conjunta. No âmbito da rede de escolas para a Saúde na Europa, existem vários projetos internacionais que integram as TIC na metodologia IVAM, que a seguir se descrevem sinteticamente.

O projeto Shape Up (SIMOVSKA, 2012; SIMOVSKA; CARLSSON, 2012; SIMOVSKA; JENSEN; CARLSSON; ALBECK, 2006) é um projeto europeu cuja ideia básica é que os/as jovens nunca deixem o ambiente de aprendizagem ou a escola sem terem desenvolvido a sua competência para tomar medidas para combater as causas profundas da obesidade (competência para a ação). Portanto, um elemento-chave do Shape Up é que os/as jovens 
colaborem com os/as adultos/as da comunidade local para agirem e influenciarem os determinantes que afetam a saúde e o bem-estar, particularmente aqueles relacionados com a obesidade infantil. Em vez de se concentrar unicamente na mudança do comportamento ou estilos de vida, abordando os riscos da obesidade como um problema de saúde, o Shape Up concentra-se em desenvolver, implementar e avaliar medidas para resolver o problema da obesidade e trazer mudanças positivas nos ambientes em que as crianças vivem, brincam e aprendem.

O projeto 'Young Minds - Exploring Links Between Youth, Culture and the Use of Alcohol' (SIMOVSKA, 2005; SIMOVSKA; JENSEN, 2003) é um projeto internacional baseado na Web, onde os/as alunos/as das turmas que participam estão envolvidos/as ativamente na decisão sobre os aspetos específicos dentro da área do álcool com que desejam trabalhar. O projeto enfatiza a colaboração transcultural usando os benefícios de envolver quatro turmas em quatro países Europeus, trabalhando no mesmo tema global ao mesmo tempo e interagindo. Neste âmbito são exploradas as possibilidades e as barreiras para integrar as TIC dentro da educação para a saúde participativa e orientada para a ação.

O projeto ‘Jovens Saudáveis em Ação’ (VILAÇA, 2006; 2008a; 2008b; 2014; VILAÇA; JENSEN, 2009, 2010; VILAÇA; SEQUEIRA; JENSEN, 2011), iniciado em 2003 e mantido até à atualidade, é um projeto de educação em sexualidade com integração das TIC, que enfatiza a colaboração entre as escolas do distrito de Braga. No projeto os/as alunos/as decidem os aspetos específicos e problemas que desejam resolver dentro da sexualidade humana. A colaboração é facilitada pela atualização continua da publicação dos trabalhos dos/as alunos/as no fim de cada fase da metodologia IVAM no Website do projeto (http://www.dct.uminho.pt/jsea/web-contrntpor/index.html) e pela existência dos seguintes e-fóruns:

Fórum da Amizade. O objetivo é os/as alunos/as criarem novos/as conhecidos/as ou amigos/as entre os/as jovens saudáveis em ação. Para isso, podem ver a apresentação dos/as participantes (no link "alunos, escola e comunidade") e decidirem quem querem conhecer. Este é um espaço para aumentar as relações pessoais entre os/as jovens do projeto. 
Fórum Diário dos Observadores. É um espaço para os/as alunos/as fazerem o registo dos dados sobre a observação das atividades da turma e refletirem sobre eles. $\mathrm{O}$ objetivo é promover a recolha de dados que serão um elemento importante de avaliação e valorização das atividades realizadas pela turma durante o projeto. Os/as alunos/as em turma, com a colaboração do/a professor/a, analisam os dados recolhidos com a sua própria turma e colaboram com as outras turmas envolvidas neste projeto, da sua e de outras escolas, comentando as seus diários publicados neste fórum. Neste contexto, pede-se aos/às alunos/as que quando mencionarem nomes de colegas, professores/as, etc. nos seus registos de observação coloquem nomes inventados. Este fórum é um instrumento privilegiado para a investigadora recolher dados sobre as percepções e concepções dos/as alunos/as e interagir com eles/as para aumentar a sua reflexividade sobre o projeto educativo no sentido de contribuir para que os/as alunos/as o melhorem continuamente.

Fórum Sexualidades ( $3^{\circ} \mathrm{Ciclo} /$ Ensino Secundário). Este fórum foi criado para os/as alunos/as receberem ajuda para as suas preocupações ou problemas relacionados com a sexualidade. Semanalmente, uma médica e uma psicóloga respondem às questões dos/as alunos/as. Os/as professores/as, pais/mães e colegas também são encorajados/as a interagir, pois parte-se do pressuposto que quem questiona deve obter o máximo de informação possível das pessoas que para eles/as são significativas, para aumentar a sua possibilidade de tomarem decisões informadas. Para respeitar a intimidade dos/as participantes pede-se aos/às alunos/as para usarem sempre um nome simulado quando colocam as suas questões, no entanto, devem colocar o seu nome verdadeiro, tal como os/as adultos/as, quando respondem às questões dos/as outros/as. Na apresentação do fórum os/as alunos/as são encorajados/as a participar, informar-se e decidir por si próprios/as quando considerarem que já refletiram o suficiente sobre os conhecimentos e os valores envolvidos nas atitudes ou comportamentos que querem clarificar. Para respeitar o desenvolvimento biopsicossocial global dos/as alunos/as, este fórum foi subdividido em dois: um destinado a alunos/as do $3^{\circ}$ ciclo $\left(7^{\circ}\right.$ ao $9^{\circ}$ ano de escolaridade, 13-15 anos) e outro para os/as alunos/as do ensino secundário ( $10^{\circ}$ ao $12^{\circ}$ ano de escolaridade, $16-18$ anos). 
Fórum Jovens em Ação. Este fórum foi criado para os/as alunos/as debaterem, receberem ajuda e trocarem ideias sobre os projetos de cada escola. Na apresentação do fórum, pede-se aos/às alunos/as para participarem e ficarem sempre online com o projeto da sua e de outras escolas, e explica-se que este espaço é para acompanharem o desenvolvimento dos projetos online das várias escolas e apresentarem os seus comentários e ideias sobre as investigações, soluções, ações e reflexões publicadas.

Outros fóruns. As turmas envolvidas têm a possibilidade de criar novos fóruns para o desenvolvimento das suas ações de promoção da saúde sexual. Ao longo dos anos de implementação deste projeto um dos fóruns que foi criado pelos/as alunos/as foi o 'Tugas/ Gaulois'. O objetivo foi estabelecer uma comunidade de aprendizagem online entre uma turma de uma escola Portuguesa e outra de uma escola Francesa. Na apresentação do fórum feita pela turma pode ler-se:

Salut! Nous sommes des élèves de l'école Professor Carlos Teixeira, située à Fafe, une petite ville au nord du Portugal. On est en train de développer un projet sur SEXUALITÉ. On aimerait connaitre la réalité $\mathrm{d}$ 'autres pays. Ainsi on vous demandera votre opinion sur quelques sujets et on vous donnera la nôtre. Nous ferons certainement des fautes parce que notre français n'est pas très fort. On demande de nous excuser pour cela. C'est que nous n'étudions le français que depuis deux ans, mais nous finirons par nous comprendre, nous sommes sûrs. ${ }^{3}$

Em seguida será apresentado um estudo de caso desenvolvido no âmbito deste projeto, que descreve um projeto baseado na escola, implementado em todas as turmas do $8^{\circ}$ ano de escolaridade (alunos/as com 14 anos). O objetivo é analisar como é que os alunos selecionam os problemas relacionados com a sexualidade para desenvolver a sua competência para a ação ${ }^{4}$ num projeto de educação em sexualidade democrática, dialógica e emancipatória baseada na metodologia IVAM, com a utilização das TIC.

\footnotetext{
3 Olá! Somos alunos/as da escola Professor Carlos Teixeira, localizada em Fafe, uma pequena cidade no norte de Portugal. Atualmente, estamos a desenvolver um projeto sobre sexualidade. Gostaríamos de conhecer a realidade de outros países. Por isso, vamos pedir a sua opinião sobre alguns assuntos e vamos também dar-lhe a nossa opinião. Certamente vamos cometer alguns erros, porque o nosso francês não é muito bom. É que nós estudamos francês só há dois anos, mas nós iremos entender-nos, temos a certeza. (TRADUÇÃO NOSSA)

${ }^{4}$ Recordar que a competência para a ação é uma competência complexa que envolve o conhecimento
} 


\section{Metodologia}

Participantes

O concelho onde se localiza a escola envolvida neste estudo é no norte de Portugal, pertence ao distrito de Braga e tem 21 freguesias com uma população residente nos Censos de 2011 de 12997 habitantes. A serra domina a paisagem de todo o concelho, com um relevo montanhoso e um inverno bastante frio, com quedas de neve e geadas frequentes, e o verão extremamente quente e seco. $O$ sector primário (fundamentalmente a agricultura), é cerca de 10\% da população, no entanto, uma vez que estamos perante um concelho cujas freguesias são, na maior parte dos casos, predominantemente rurais, a agricultura surge, essencialmente, como uma atividade secundária na estrutura de ocupações da população do concelho e muitos/as produtores/as agrícolas singulares têm uma atividade profissional exterior remunerada, que é considerada como a sua atividade profissional principal. Enquanto atividade complementar de outras ou de subsistência, o sector primário tende a assumir uma grande expressividade. Neste estudo de caso foram envolvidas as quatro turmas do $8^{\circ}$ ano de uma escola desse concelho, incluindo 44 rapazes e 48 meninas ( $N=92)$, com uma média de idades de 13.8 anos (mínimo $=13$ anos, máximo $=17$ anos, DP $=.46$ ).

\section{Fontes de dados}

Os dados foram recolhidos por observação com elaboração de notas de campo e através dos documentos publicados pelos/as alunos/as no Website do projeto.

\section{Tratamento e análise de dados}

A análise de dados foi feita pela criação de um sistema de categorias indutivo (Bardin,1997). Após a leitura na integra das notas de campo e do material publicado online foi criado um sistema de categorias e subcategorias mutuamente exclusivas para agregar os dados que emergiram. Para aumentar a confiabilidade da análise, a autora repetiu a codificação dos resultados, aproximadamente um mês depois, e solicitou a uma das professoras envolvidas, com formação em análise qualitativa, para fazer uma

sobre as consequências e causas do problema, visões, ações e mudança, e comprometimento dos alunos com a ação. 
codificação independente. Quando houve discrepância entre os três momentos de codificação, as discrepâncias foram discutidas entre as duas investigadoras. Se não se chegou a consenso, os dados não foram introduzidos na codificação final.

Os resultados serão apresentados na forma de tabelas, com indicação das subcategorias criadas e dos grupos de alunos/as cujas respostas fizeram emergir essas subcategorias. Por vezes, também serão apresentados excertos das notas de campo escritas pela autora deste estudo, para enriquecer os dados em análise.

\section{Resultados}

\section{Concepções iniciais dos/as alunos/as sobre sexualidade}

As professoras decidiram, após consultar os/as alunos/as, começar o projeto pela apresentação dos alunos/as, da escola e da comunidade para facilitar a sua interação online com as outras escolas envolvidas no projeto (Figura 2).
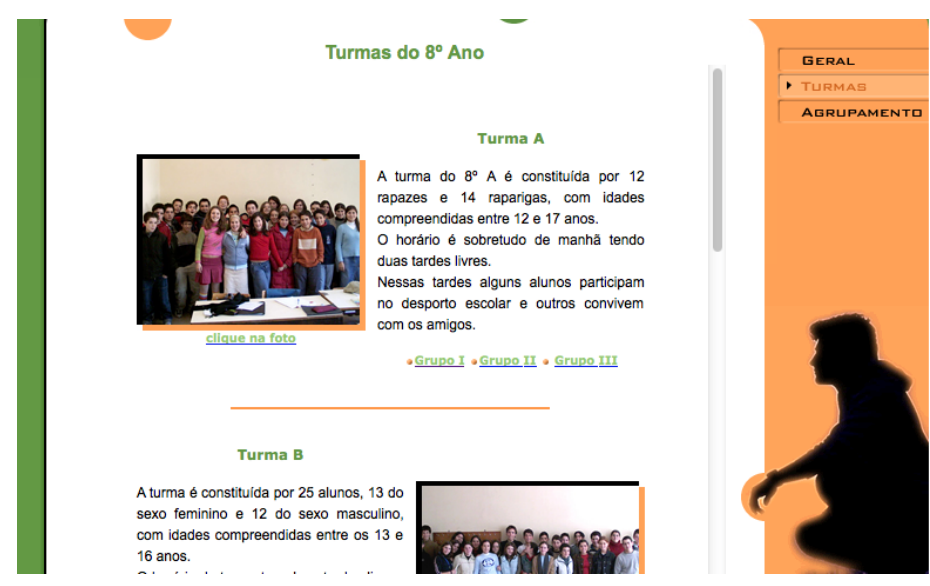

Figura 2: Apresentação dos/as alunos/as.

Fonte: Website Jovens Saudáveis em Ação.

Posteriormente, os alunos para decidirem o que gostariam de investigar dentro da educação em sexualidade, apresentaram em pequeno grupo, com partilha posterior em turma e em assembleia com as quatro turmas, as suas ideias iniciais sobre o que é a sexualidade e a educação em sexualidade. A figura 3 apresenta uma síntese das ideias finais da assembleia entre turmas sobre o que é a sexualidade, proposta inicialmente por uma das turmas. 


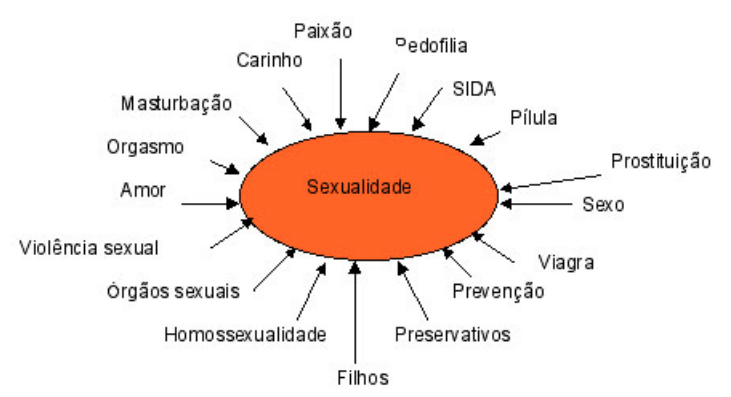

Figura 3: Ideias iniciais dos/as alunos/as sobre sexualidade

Fonte: Website Jovens Saudáveis em Ação

Verificou-se que para estes/as alunos/as, os principais conceitos-chave sobre a sexualidade humana são no âmbito dos relacionamentos (paixão, amor, carinho, filhos/as), cultura, sociedade e direitos humanos (pedofilia, prostituição, violência sexual), desenvolvimento humano (órgãos sexuais), comportamento sexual (sexo, orgasmo, masturbação, viagra, homossexualidade) e saúde sexual e reprodutiva (Sida/AIDS, pílula, prevenção, preservativos), estando principalmente focados em tópicos relacionados com a sexualidade e direitos humanos, comportamento sexual e saúde sexual e reprodutiva. Estes conceitos-chave, incluindo outros tópicos mais alargados e o trabalho com a clarificação de valores, as atitudes e competências, são os tópicos defendidos pela UNESCO (2009 a, 2009b), pela WHO-Europe \& FCHE, BZgA (2010) e pelo Governo Português (PORTUGAL - MINISTÉRIOS DA EDUCAÇÃO E DA SAÚDE, 2010) para a educação em sexualidade.

\section{Seleção e investigação dos problemas de educação em sexualidade pelos/as alunos/as}

$\mathrm{Na}$ assembleia entre turmas, anteriormente referida, face a várias sugestões de atividades possíveis apresentadas pelas professoras, os/as alunos/as decidiram optar por investigar as manifestações da sexualidade em obras de arte, no nosso quotidiano, as mensagens que recebem sobre sexualidade, os carinhos e intimidades que consideram corretos em cada fase da vida, como se sentem quando falam de intimidade, as diferentes dimensões da sexualidade (biológica, psicológica, cultural e ética) e as diferentes concepções e vivências da sexualidade em diferentes culturas e ao longo do tempo. 
Também ficou decidido publicarem o resultado das suas investigações no Website do projeto e partilharem os seus comentários sobre as conclusões a que chegou cada turma.

Em seguida apresentam-se os resultados de uma destas investigações, cujo objetivo foi refletir sobre a evolução da sexualidade evidenciada em duas telenovelas, selecionadas pelos/as alunos/as ('Chocolate com Pimenta’ e ‘Morangos com Açúcar’).

\section{Autoimagem}

De acordo com a percepção dos sete grupos (G), há diferenças nos objetos que identificam as pessoas em diferentes épocas (Tabela 1).

Na década de 1920 foi identificado como roupa típica dos homens o fato e o chapéu $\left(G_{2}\right)$ e das mulheres os vestidos compridos e o chapéu $\left(G_{2}, 7\right)$, em oposição à telenonovela atual onde vestiam mini-saia e roupa decotada (G7). Todos/as referiram que enquanto em 1920 as roupas eram antigas, atualmente todos/as vestem roupa de "marca". Os grupos G1 e G2 referiram que no passado havia diferenças na forma de vestir em função do poder económico. Outro objeto que caraterizava a forma de ser das pessoas era o carro. Em 1920 os carros eram antigos (G1, 2, 3, 5 e 6) e muitos eram velhos (G1), enquanto atualmente a maior parte dos carros são bons ( $\mathrm{G} 1 \mathrm{a} G 7)$. Nas duas épocas os ricos tinham carros melhores $\left(G_{2}, 4\right)$, mas em 1920 as pessoas mais pobres não tinham carros, o que não acontece agora (G2). 


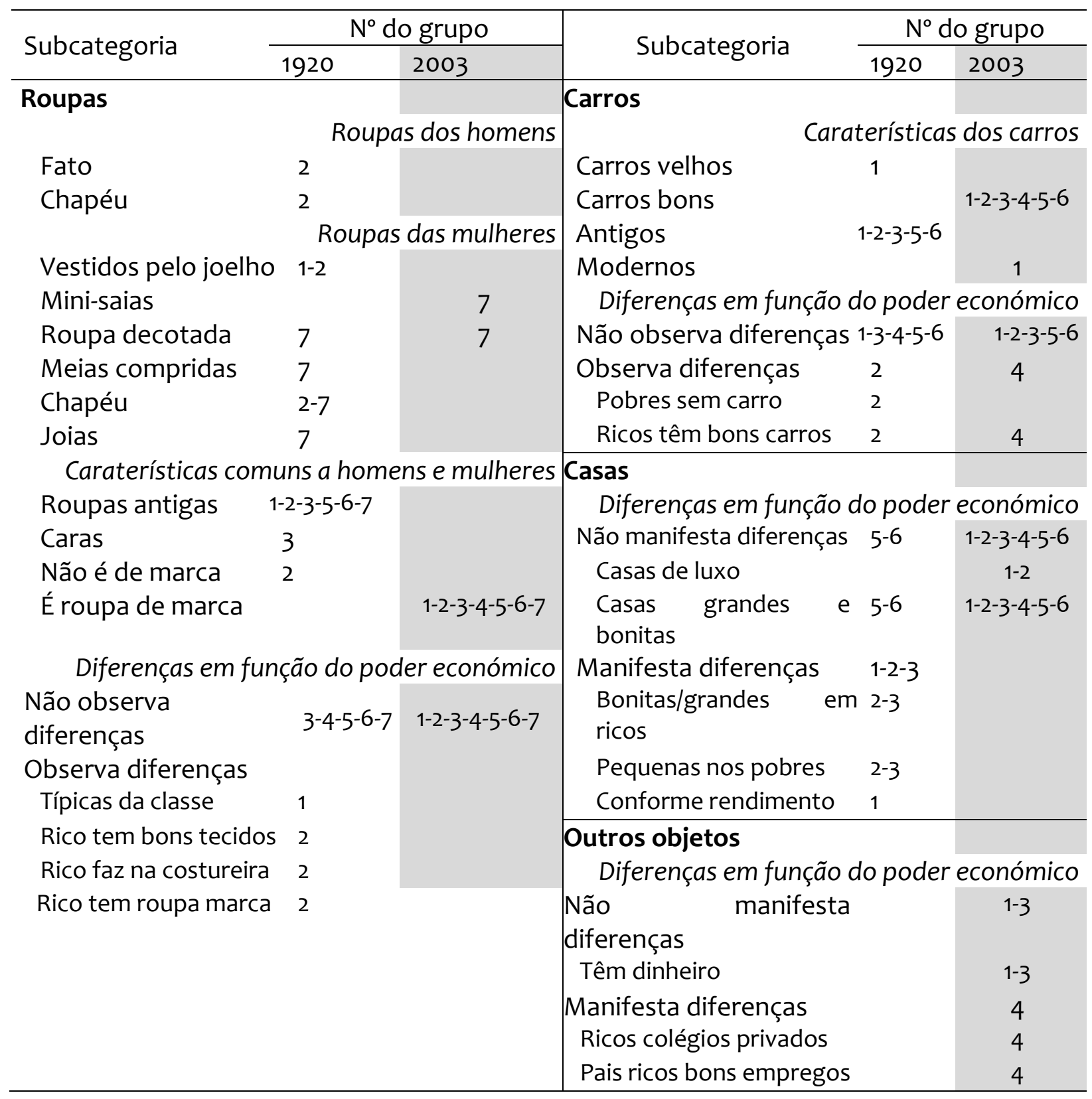

Tabela 1: Objetos que identificam as personagens nas novelas de épocas diferentes. Fonte: Autor.

As casas atuais foram identificadas por todos os grupos como grandes e bonitas e no passado como pequenas nos pobres ( $\mathrm{G}_{2}$ e 3 ) e grandes e bonitas nos ricos ( $\mathrm{G}_{2}$ e 3), embora dois grupos ( $G_{5}$ e 6 ) tivessem considerado que em 1920 a maior parte das casas era grande e bonita independentemente do poder económico. Outras diferenças encontradas pelos/as alunos/as estão relacionadas com a atualidade, tendo sido identificado mais dinheiro nas pessoas ( $\mathrm{G}_{1}$ e 2 ) e diferenças entre ricos e pobres no acesso à qualidade de estudos e no emprego dos pais (G4). 
Os grupos em estudo também observaram diferenças na imagem corporal e traços de personalidade nas personagens das duas épocas (Tabela 2).

\begin{tabular}{|c|c|c|c|c|c|}
\hline \multirow{2}{*}{ Subcategoria } & \multicolumn{2}{|c|}{$\mathrm{N}^{\circ}$ do grupo } & \multirow{2}{*}{ Subcategoria } & \multicolumn{2}{|c|}{$\mathrm{N}^{\circ}$ do grupo } \\
\hline & 1920 & 2003 & & 1920 & 2003 \\
\hline \multicolumn{3}{|l|}{ Imagem corporal } & \multicolumn{3}{|c|}{ Traços de personalidade (cont.) } \\
\hline \multicolumn{3}{|c|}{ Imagem dos homens } & Alguns/mas delicados/as & $1-3$ & $1-3-4$ \\
\hline Boa aparência & $1-3$ & $1-3-4$ & Maioria vaidosos/as & 3 & \\
\hline Jovens & & 4 & Envergonhadas & 7 & 3 \\
\hline \multicolumn{3}{|c|}{ Imagem das mulheres } & Espírito realista & & 1 \\
\hline Jovens & 1 & 4 & Maioria autoritários & & $1-3-4$ \\
\hline Bonitas & $1-2-3-6$ & $1-3-4$ & $\begin{array}{l}\text { Alguns/mas } \\
\text { apaixonados/as }\end{array}$ & 3 & 4 \\
\hline Grandes penteados & 1 & & Alguns/mas sentem amor & & 4 \\
\hline \multicolumn{3}{|c|}{ Diferenças em função do poder económico } & Alguns/mas amigos/as & 3 & 4 \\
\hline Só as mulheres ricas são belas & 2 & & Alguns/mas sentem ódio & 5 & 4 \\
\hline Ricas vão à cabeleireira & 2 & & $\begin{array}{l}\text { Alguns/mas têm } \\
\text { rancor/raiva }\end{array}$ & 5 & 4 \\
\hline Ricas compram maquilhagem & 2 & & Alguns/as são gananciosas & 1 & \\
\hline Traços de personalidade & & & Maioria invejosos/as & 3 & \\
\hline Pais não dão liberdade às filhas & 2 & & Às vezes são agressivos/as & & $1-3-4$ \\
\hline Mães protegem filhos/as o máximo & 5 & & Às vezes são vingativos & & 4 \\
\hline Filhas não têm liberdade & 2 & & Fazem o que querem & & 1 \\
\hline $\begin{array}{l}\text { Pais/mães mostram interesse } \\
\text { filhos/as }\end{array}$ & e 5 & & Cuidam tarefas domésticas & & 5 \\
\hline Delicadeza entre namorados & 2 & & Alguns drogam-se & & 4 \\
\hline Maioria simpáticos/as & 1 & $1-3-4$ & Uma sofre de anorexia & & 4 \\
\hline
\end{tabular}

Tabela 2: Imagem corporal e traços de personalidade das personagens nas novelas de épocas diferentes. Fonte: Autor.

Consideraram que nas duas épocas a maior parte das mulheres retratada era jovem e bonita para a época, mas apenas na novela recente foi mais referida a boa aparência da maior parte dos homens e o facto de aparecerem muitos jovens. Também assinalaram traços de personalidade diferentes para homens e mulheres em função da época. Consideraram que na década de 1920 a maior parte das meninas não tinha liberdade (G2), as mulheres protegiam os/as filhos/as ao máximo (G5) e os pais e mães mostravam interesse nos filhos/as (G5). Estes traços de personalidade não foram referidos a propósito da telenovela atual. A delicadeza entre namorados (G2), a vaidade da maior parte dos/as personagens (G3), a ganância (G1) e a inveja (G3) só foram identificados em 
1920. Houve traços de personalidade que apenas foram identificados na novela atual, nomeadamente o espírito realista $\left(G_{1}\right)$ e autoritário $\left(G_{1}, 3\right.$ e 4$)$, o serem às vezes agressivos ( $\mathrm{G} 1,3$ e 4 ) e vingativos (G4), fazerem o que querem (G1), cuidarem das tarefas domésticas (G5), e alguns drogarem-se e uma sofrer de anorexia (G4). Houve ainda traços comuns às personagens das duas épocas, como a simpatia e delicadeza da maior parte das personagens dos dois sexos, a vergonha de senhoras/meninas, personagens que estavam apaixonadas, eram amigas de outras ou, pelo contrário, sentiam ódio e raiva.

Estas professoras discutiram com os/as alunos/as alguns aspetos-chave da influência dos mass media nos modelos de beleza e na autoimagem, e das implicações da autoimagem na vivência da sexualidade. Ao discutirem a evolução do que é ser uma mulher bela ou um homem com boa aparência ao longo das décadas, realçaram o confronto de uma imagem corporal estática versus um conceito de beleza ativo, que associa o novo conceito de imagem corporal ao desenvolvimento de valores e qualidades que sejam atraentes e sedutoras para a própria pessoa e para os outros/as. Nesta sequência, enfatizaram o conceito de imagem corporal, como a representação mental sobre o próprio corpo, unida às atitudes e sentimentos que este desperta nos outros/as, mostrando que, por essa razão:

evolui ao longo da vida do indivíduo, fundamentalmente em função das experiências sensoriais e das relações do corpo com o meio externo e as pessoas que o rodeiam. A professora A aproveitou este contexto para explicar aos adolescentes que eles por vezes vivem com uma certa ansiedade e sentem vergonha sobre as mudanças que estão a aparecer no seu corpo e, ainda por cima, os estereótipos de beleza e as destrezas corporais que evidenciam ainda os fazem sentir em mais desvantagem. Em seguida, questionou-os: "Já observaram alguém ser pressionado, pelo seu grupo de amigos ou entre os colegas, para ser como estes estereótipos? Por exemplo, chamar gorda/o e dizer que tem que emagrecer, ou que tem que aumentar a massa muscular, ou usar sapatilhas de uma determinada marca?". (Nota de campo)

No final desta discussão, os/as alunos/as identificaram como problemas que gostariam de resolver: i) a dificuldade dos/as amigos/as e da família em analisarem criticamente os aspetos negativos da influência da TV na sexualidade das pessoas; ii) aprender a valorizar na comunidade escolar uma visão dinâmica e não estática da 
autoimagem. Consideram que poderiam contribuir para a resolução destes problemas educando os/as outros/as sobre o assunto, como aconteceu com eles/as.

\section{Tipo de comunicação e papéis desempenhados pelas personagens}

Tal como nas dimensões de análise anteriores, os grupos observaram diferenças no tipo de comunicação e na linguagem que utilizavam as personagens nas duas épocas (Tabela 3).

\begin{tabular}{|c|c|c|}
\hline \multirow{2}{*}{ Subcategoria } & \multicolumn{2}{|c|}{$\mathrm{N}^{\circ}$ do grupo } \\
\hline & 1920 & 2003 \\
\hline \multicolumn{3}{|l|}{ Tipo de comunicação } \\
\hline Algumas personagens são passivas & $1-2-3-4-5-6-7$ & 2 \\
\hline Algumas personagens são calmas & & $1-2-3-4-5$ \\
\hline Entre amigos e pais é calma & & 4 \\
\hline Entre amigos é assertiva & & 2 \\
\hline $\begin{array}{l}\text { Alguns filhos têm uma comunicação agressiva com os } \\
\text { pais }\end{array}$ & & 2 \\
\hline A maior parte dos filhos são passivos com os pais & & 2 \\
\hline Entre rivais é agressiva & & 4 \\
\hline Algumas personagens são agressivas & $1-2-3-4-5-6-7$ & $1-2-3-4-5$ \\
\hline A maior parte das vezes são agressivas & 3 & \\
\hline \multicolumn{3}{|l|}{ Tipo de linguagem } \\
\hline Linguagem familiar & $1-2$ & $1-2-3-4-5$ \\
\hline $\begin{array}{l}\text { Geralmente utilizam uma linguagem familiar, mas por } \\
\text { vezes utilizam uma linguagem cuidada }\end{array}$ & $3-4-5-6-7$ & \\
\hline
\end{tabular}

Tabela 3: Tipo de comunicação e linguagem das personagens nas novelas de épocas diferentes. Fonte: Autor.

Embora a maior parte dos/as alunos/as tivesse considerado que nas duas épocas havia algumas personagens com um estilo de comunicação passivo ou agressivo, o $\mathrm{G}_{3}$ considerou que na década de 1920 a maior parte das vezes as personagens são agressivas. Na novela atual, a maioria considerou que algumas personagens são calmas ( $G 1$ a $G$ 5), nomeadamente quando conversam entre amigos ou quando os pais/mães conversam entre eles (G4). Os grupos consideraram que na novela atual entre amigos/as são assertivos/as (G2), são agressivos/as entre rivais $\left(G_{4}\right)$ e alguns nas conversas com os pais/mães, embora a maior parte seja passiva (G2). O tipo de linguagem na novela de 1920 era cuidada ( $G 1$ a $G$ 7), apenas com alguma linguagem familiar ( $G 1$ e 2) e na novela atual 
era sempre familiar. Os papéis sociais desempenhados pelos personagens foram identificados como sendo diferentes nas duas épocas. Em 1920 apenas os homens estavam preocupados com o desempenho na sua profissão ( $(G 1,2$ e 3) e, atualmente, além dos homens, as mulheres ( $\mathrm{G}_{1}$ a 4 ) e os/as jovens ( $\mathrm{G}_{3}$ e 4 ) também estão preocupados/as com o seu desempenho profissional.

Os valores sobre o comportamento sexual e a família foram considerados muito diferentes nas duas épocas. Em 1920 as mulheres só tinham relações sexuais depois do casamento (G5) e os pais proibiam os filhos e filhas de terem relações sexuais na adolescência (G2), o que não foi identificado por nenhum dos grupos na novela atual (Tabela 4).

\begin{tabular}{|c|c|c|}
\hline \multirow{2}{*}{ Subcategoria } & \multicolumn{2}{|c|}{$\mathrm{N}^{\circ}$ do grupo } \\
\hline & 1920 & 2003 \\
\hline \multicolumn{3}{|l|}{ Quando têm relações sexuais } \\
\hline As mulheres só têm relações sexuais depois do casamento & 5 & \\
\hline Os pais proíbem os filhos/as de ter rel. sexuais na adolescência & 2 & \\
\hline Os adolescentes têm relações sexuais & & $1-2-3-4$ \\
\hline \multicolumn{3}{|l|}{ Valores sobre o comportamento sexual e família } \\
\hline As mulheres têm que casar virgens & $2-3-4$ & \\
\hline Não se valoriza a virgindade & & 2 \\
\hline É correto os/as adolescentes terem relações sexuais & & $2-3-4$ \\
\hline Só podem ter relações sexuais quando estão casados/as & $1-2-3-4$ & \\
\hline As famílias devem ser constituídas por pai, mãe e filhos/as & 2 & \\
\hline O mais correto é ter filhos dentro de uma família moderna & & $3-4$ \\
\hline Só pode haver filhos/as depois do casamento & $2-3$ & \\
\hline A família tradicional é a família desejável & & $2-3-4$ \\
\hline É normal haver famílias monoparentais & & $1-4$ \\
\hline \multicolumn{3}{|l|}{ Conversas sobre sexualidade } \\
\hline Praticamente não existem & 1 & \\
\hline Só podem existir com os pais & 2 & \\
\hline É normal existirem com os pais & 2 & $1-2-3-4$ \\
\hline Poucas entre amigos adolescentes & 2 & \\
\hline É normal existirem entre adolescentes amigos/as & & $1-2-3-4$ \\
\hline Entre adultos homens & 2 & \\
\hline É normal existirem entre adultos/as & & $3-4$ \\
\hline Entre namorados & & $1-2-3-4$ \\
\hline
\end{tabular}

Tabela 4: Valores sobre sexualidade dos pais/mães e filhos/as nas novelas de épocas diferentes. Fonte: Autor. 
Enquanto em 1920 as mulheres tinham de casar virgens ( $\mathrm{G} 2$ a 4) e só podia haver sexo no casamento ( $(\mathrm{G} 1 \mathrm{a}$ 4) para ter filhos (G2), na novela atual não se valoriza a virgindade (G2), é correto os adolescentes terem relações sexuais ( $\mathrm{G}_{2}$ a 4) e, embora a família tradicional ( $\mathrm{G}_{2}$ a 4) com filhos ( $\mathrm{G}_{3}$ e 4) seja o desejável, as famílias monoparentais são normais (G1 e 4). Em relação às conversas sobre sexualidade, a única caraterística considerada comum nas duas épocas foi conversar com os pais sobre sexualidade. Em 1920 praticamente não existiam essas conversas (G1), só podiam existir com os pais (G2) e algumas com os amigos e entre adultos homens (G2). Na novela atual, é normal falar sobre sexualidade com os/as amigos/as ( $G_{1}$ a 4), adultos/as (G3 e 4) e namorados (G1 a 4). Só foram indicados os temas das conversas sobre sexualidade na novela atual, que incluíram o valor que os pais dão aos filhos (G1 e 2), sexualidade e namoro (G2 e 4), o que está certo ou errado na sexualidade (G2), prevenção da gravidez e de ISTs (G2 e 4) e o valor da família tradicional (G2 e 4) e da família monoparental (G1 e 4).

Esta análise permitiu às professoras discutirem na assembleia inter-turmas com os alunos os estereótipos e os valores sobre a sexualidade transmitidos pelos media, os elementos sexistas ou discriminatórios para o homem ou para a mulher que encontraram em cada época, a razão por que se utilizava tanto o sexo nos filmes e a influência que os filmes/novelas tinham nos/as jovens e adultos/as. Nesta discussão, observei que os/as alunos/as consideravam que a maior parte das telenovelas e publicidade, quer pelo tipo de mensagem destinada ao homem ou à mulher, quer pelos papéis de género que veiculavam, tinham um forte potencial sexista. O termo sexismo foi utilizado para descrever todo o tipo de comportamentos ou situações que implicaram a discriminação das mulheres e pressupunham que as mulheres tinham capacidades e características inferiores aos homens devendo, por isso, limitar-se aquilo que os estereótipos tradicionais dos papéis de género lhes impunham. Os/as alunos concluíram que embora com maior predomínio em 1920, estes estereótipos ainda persistiam na novela atual. A partir dos resultados obtidos nos grupos de alunos/as deste estudo, as professoras também valorizaram a importância dos estilos de comunicação (assertiva, passiva, agressiva e manipuladora) na promoção de sexualidades saudáveis, a análise da evolução dos valores sexuais ao longo da história, e em diferentes culturas, e os temas de promoção da saúde sexual que abordam. É de realçar que o que chamou a atenção dos/as 
alunos/as nos temas tratados na novela atual foram os valores relacionados com a sexualidade, o comportamento sexual no namoro, o conceito de família, a prevenção de infeções sexualmente transmissíveis e a prevenção da gravidez não planeada.

No final desta discussão, estes/as alunos/as identificaram como problemas que gostariam de resolver: i) existirem estereótipos de género que prejudicam as pessoas; ii) falta de competências para terem comunicações assertivas entre namorados/as; iii) prevenção da gravidez não planeada; iv) prevenção das infeções sexualmente transmissíveis.

\section{Discussão e conclusões}

Ao analisar como é que os/as alunos/as selecionam os problemas relacionados com a sexualidade para planificar posteriormente os seus projetos orientados para e ação e desenvolver a sua competência para a ação, foi possível chegar a quatro conclusões principais. Em primeiro lugar, as professoras que fizeram parte deste estudo foram capazes de aplicar uma metodologia de ensino democrática, crítica e emancipatória porque fundamentaram o seu ensino em três aspetos principais: i) criaram condições para que os/as alunos/as fizessem a sua aprendizagem baseada numa investigação planificada por eles/as, com as professoras assumindo o papel de facilitadoras da aprendizagem; ii) estas investigações envolveram a participação genuína dos/as alunos/as, pois foram eles/as que decidiram os problemas que queriam investigar e as estratégias para o fazer; iii) criaram condições para que os/as alunas divulgassem e discutissem publicamente os resultados da sua aprendizagem, quer presencialmente quer online, para encorajarem a comunidade a resolver os problemas identificados. Estes resultados mostraram que tal como noutros contextos e com outros temas de educação para a saúde (SIMOVSKA, 2005, 2012; SIMOVSKA; CARLSSON, 2012; SIMOVSKA; JENSEN; CARLSSON; ALBECK, 2006; VILAÇA, 2008a; 2008b; 2014; VILAÇA; JENSEN, 2009, 2010; VILAÇA; SEQUEIRA; JENSEN, 2011), a metodologia IVAM com integração das TIC é um instrumento útil para aumentar a participação dos alunos nos projetos educativos e desenvolver a sua competência para a ação.

Em segundo lugar, as TIC foram integradas intencionalmente no desenho da investigação para potenciar a recolha de dados online, e no desenho da intervenção 
pedagógica para aumentar o aprofundamento da interação entre a comunidade colaborativa de aprendizagem a três níveis de interação: entre adultos/as, entre adolescentes e entre adolescentes e adultos/as. A utilização das tecnologias para visualização de telenovelas e a publicação da sua análise no Website do projeto facilitou a identificação e discussão de problemas online relacionados com a sexualidade que era do interesse dos alunos resolver. Esta fase foi crucial para o desenvolvimento dos projetos orientados para a ação de promoção de sexualidades saudáveis.

Em terceiro lugar, a maior parte dos resultados obtidos na caraterização da evolução histórica dos fatores associadas à autoimagem é semelhante aos resultados encontrados em outros estudos realizados em Portugal (ex., RODRIGUES; VILAÇA, 2013; VILAÇA, 2014), nomeadamente: i) o uso de roupa de marca como símbolo atual do poder económico dos/as jovens e de aceitação no seu grupo de pares, sem distinção de classe social, percepcionados por estes/as alunos/as como uma evolução das diferentes formas de vestir associadas à grande distinção de classes que existia no passado; ii) o carro percepcionado como um símbolo do poder económico no passado não foi uma caraterística distintiva na atualidade; iii) o tamanho e a estética das casas foram associadas por alguns grupos à imagem pessoal nas duas épocas. Neste âmbito da influência dos meios de comunicação de massa na autoimagem, é importante discutir criticamente as razões por que a acomodação aos estereótipos existentes se relaciona positivamente com a maior popularidade, maior segurança em si mesmo, autoconfiança, maior implicação em relações heterossexuais, maior equilíbrio pessoal, etc.. Também é critico discutir-se o facto de nos meios de comunicação de massa, como se observou nas duas décadas, a feminilidade da mulher ser valorizada por um conceito de beleza estático, onde predomina a beleza física em detrimento dos seus valores morais, capacidades de interação social, sucesso profissional e, até mesmo, da sua capacidade para seduzir. Além disso, é importante discutir por que é que a mulher é descrita como devendo ser afetiva, dependente, sensível, cuidadosa, interessada pelo bem estar dos outros e sentir-se atraída pelos homens e desejada por eles e, pelo contrário, o homem deverá ter um corpo másculo, ser seguro, empreendedor, duro, ativo, independente, agressivo e sentir-se atraído pelas mulheres e desejado por elas. A mensagem que se transmitia em 1920 às crianças, era que os meninos viriam a ter profissões muito importantes e as meninas 
seriam boas donas de casa e mães de família. Embora exista uma evolução na sociedade, estas mensagens subsistem na atualidade.

Dependo do desenvolvimento psicossexual dos/as alunos/as, é possível discutir ainda que quando alguém compara o seu parceiro/a amoroso/a com o ideal comercializado, visto nas novelas ou na publicidade, tem muitas probabilidades de ficar desapontado/a. Esse desapontamento pode levar à frustração e a uma fogosidade média que pode ser transformada numa comunicação e relacionamento sexual pobre, que tem probabilidade de resultar na diminuição da satisfação sexual. Além disso, a pressão para ser um/a parceiro/a como o/a das novelas ou dos anúncios pode-o/a levar a sentir-se envergonhada/o com o seu próprio corpo ou a sentir-se inferior, o que poderá levar a disfunções sexuais. Por exemplo, se a mulher está muito preocupada com as suas ações ou aparência, pode não lubrificar o suficiente ou o homem pode não conseguir manter uma ereção suficientemente longa.

É de salientar, que neste estudo emergiram dois fatores novos. O primeiro, foi o acesso a escolas de qualidade, não o acesso à escola, que foi percepcionado na atualidade como uma manifestação do poder económico e da autoimagem. Este fator possibilita a introdução no processo educativo da educação inclusiva como tema emergente dos Objetivos do Desenvolvimento Sustentável (UN, 2015). O segundo fator foram as semelhanças e diferenças encontradas nas relações interpessoais. Estes/as alunos/as percepcionaram a falta de liberdade das meninas, a proteção dos/as filhos/as pela família, a delicadeza entre namorados, a vaidade dos homens e mulheres retratados e, por vezes, a ganância e a inveja como características pessoais do passado. Pelo contrário, associaram aos/às jovens da sua época a agressividade, o autoritarismo e, por vezes, o uso de drogas e distúrbios alimentares como a anorexia. Por outro lado, também Ihes associaram caraterísticas como a liberdade, o realismo e a partilha de tarefas domésticas, independentemente de serem rapazes ou meninas. Estas diferenças fizeram emergir mais dois tópicos educativos que interessa discutir na comunidade educativa numa perspetiva de promoção da saúde (SHE, 2009), nomeadamente: a possível relação entre a forma como percepcionaram o apoio da família e a delicadeza entre os namorados no passado e a agressividade e autoritarismo dos jovens na atualidade, bem como o seu uso de drogas ou a existência de distúrbios alimentares. 
Em quarto lugar, apesar dos alunos terem percepcionado que as preocupações profissionais deixaram de ser só do homem e passaram a ser também da mulher, e que os valores sobre o comportamento sexual e o diálogo sobre eles evoluíram para uma maior liberdade sexual dos rapazes e meninas e uma maior abertura nas conversas com o pai, mãe, amigos e adultos, em geral, continua a ser crítico discutir o conjunto de crenças, atitudes, comportamentos e ideologias que na maior parte das sociedades mostram um claro predomínio do sexo masculino sobre o feminino, embora na novela atual isso esteja mais camuflado. Dependendo da maturidade dos/as alunos/as também é importante debater que o uso do sexo para aumentar a audiência das telenovelas ou vender produtos não relacionados com a sexualidade é exploração sexual. Quando estas mensagens entram do dia-a-dia nas nossas casas através da televisão, as pessoas têm mais probabilidade de ver os outros como objetos sexuais o que interferirá não só nas suas relações interpessoais, mas também na sua satisfação pessoal. As façanhas sexuais e as carícias e os beijos que levam a desmaios, também podem levar as pessoas a pensarem que têm obrigação de sentir ou fazer o mesmo, mesmo que sejam situações ou comportamentos impossíveis de viver por pessoas reais.

Este estudo, apesar das limitações inerentes a um estudo de caso, tem implicações importantes na investigação e prática da educação em sexualidade, pois é um exemplo da operacionalização a nível de práticas letivas e de investigação em educação em sexualidade democrática, dialógica e emancipatória baseada na metodologia IVAM, com integração das TIC. 


\section{Referências}

BARDIN, LAURENCE. (1997). Análise de conteúdo. Lisboa: Edições 70.

AUSTRALIA. DEPARTMENT OF EDUCATION OF AUSTRALIA. ACARA Australian Curriculum Consultation Portal. Australia, 2010. Acedido

em: http://www.acara.edu.au/curriculum/consultation.html

JENSEN, BJARNE BRUUN. Action, action competence and change in the field of environmental and health education. In: JENSEN, BJARNE BRUUN;

SCHNACK, KARSTEN (Ed.). Action and Action Competence as Key Concepts in Critical Pedagogy. Copenhagen: Didaktiske Studier, Royal Danish School of Educational Studies, 1994. p. 73-85.

JENSEN, BJARNE BRUUN. A case of two paradigms within health education. Health Education Research, Oxford, v. 12, n. 4, p. 419-428, 1997.

JENSEN, BJARNE BRUUN. Participation, commitment and knowledge as components of pupil's action competence. In: JENSEN, BJARNE BRUUN; SCHNACK, KARSTEN; SIMOVSKA, VENKA (Ed.). Critical Environmental and Health Education. Research Issues and Challenges. Copenhagen: Res. Centre for Env. and Health Ed. The Danish University of Education, 2000. p. 219-237.

JENSEN, BJARNE BRUUN; NIELSEN, KIRSTEN. Activities, action and action competence. In: BREITING, SOREN; NIELSEN,KIRSTEN (Eds.). Environmental Education Research in the Nordic Countries. Copenhagen: The Royal Danish School of Educational Studies. 1996, p.120-143.

JENSEN, BJARNE BRUUN; SCHNAK, KARSTEN. Action competence as an educational challenge. In JENSEN, BJARNE BRUUN; SCHNACK, KARSTEN (Eds.). Action and Action Competence as Key Concepts in Critical Pedagogy. Copenhagen: Didaktiske Studier, Studies in Educational Theory and Curriculum, Royal Danish School of Educational Studies, 1994. p. 5-18.

MARTINHO, TÂNIA. Potencialidades das TIC no Ensino das Ciências Naturais - um estudo de caso. 2008. 195f. Dissertação (Mestrado em Multimédia em Educação), Universidade de Aveiro, Aveiro, Portugal, 2008.

PORTUGAL. Ministérios da Saúde e da Educação. Regulamentação da Lei nº 60/2009, de 6 de agosto. Portaria n 196-A/2010 de 09 de abril, D.R. I Série, nº 69. Lisboa, 2010.

RODRIGUES, CRISTINA DE JESUS \& VILAÇA, TERESA. Educação em Sexualidade na Educação Moral e Religiosa Católica no $7^{\circ}$ ano de escolaridade em Portugal, Revista IberoAmericana de Estudos em Educação, Araraquara/ Brasil; Alcalá/ Espanha, v. 8, n.3, p. 561576, 2013. 
SHE-SCHOOLS FOR HEALTH IN EUROPE. Better schools through health Vilnius Resolution. In: RAGAIŠIENE, IRENA (Eds.). Better Schools Through Health: the third European Conference on Health Promoting Schools, held in Vilnius, Lithuania, 15-17 June 2009. Lithuania: NIGZ, State Environmental Health Centre of Lithuania.

SIMOVSKA, VENKA. Participation and learning about health. In CLIFT, STEPHEN; JENSEN, BJARNE BRUUN (Eds.). The Health Promoting School: International Advances in Theory, Evaluation and Practice. Copenhagen: Danish University of Education Press, 2005, p.173-192.

SIMOVSKA, VENKA. Case Study of a participatory health-promotion intervention in school, Democracy \& Education, Portland, Oregon, v. 20, n.1, p. 1-10, 2012.

SIMOVSKA VENKA; CARLSSON, MONICA. Health-promoting changes with children as agents: findings from a multiple case study research, Health Education, Oxford, v.112, n. 3, p. 292-304, 2012.

SIMOVSKA, VENKA; JENSEN, BJARNE BRUUN. Young-minds.net/lessons learnt: student participation, action and cross-cultural collaboration in a virtual classroom. Copenhagen: Danish University of Education Press, 2003.

SIMOVSKA, VENKA; JENSEN, BJARNE BRUUN; CARLSSON, MONICA; ALBECK, C. Shape up Europe: Towards a healthy and balanced growing up. Barcelona: P.A.U. Education, 2006.

UNESCO - THE UNITED NATIONS EDUCATIONAL, SCIENTIFIC AND CULTURAL ORGANIZATION. International technical guidance on sexuality education. Rationale for sexuality education (Vol. I). Paris: UNESCO, 2009 a.

UNESCO - THE UNITED NATIONS EDUCATIONAL, SCIENTIFIC AND CULTURAL ORGANIZATION. International technical guidance on sexuality education. Topics and learning objectives (Vol. II). Paris: UNESCO. $2009 \mathrm{~b}$.

UN- UNITED NATIONS GENERAL ASSEMBY. Resolution adopted by the General Assembly on 25 September 2015, 2015. Acedido

em http://www.un.org/ga/search/view_doc.asp?symbol=A/RES/70/1\&Lang=E

VILAÇA, TERESA. Development Dynamics of Action-Oriented Learning on Health Education. In: MUÑOZ, MARIO; JELÍNEK, IVAN; FERREIRA, FERNANDO (Org.). Proceedings of the IASK International Conference Teaching and Learning. Aveiro: IASK; Univ. de Aveiro, 2008a p. 74-83.

VILAÇA, TERESA. The Roles of Biological Knowledge While Exploring Action- Oriented Knowledge and the S-IVAC Methodology in Sex Education. In: RAICHVARG, DANIEL (Ed.). BioEd 2008 International Conference Biological Sciences Ethics and Education: The Challenges of Sustainable Development. France, Dijon: University of Burgundy, 2008b. 
VILAÇA, TERESA. Metodologia de ensino para uma sexualidade positiva e responsável. ELO Revista do Centro de Formação Francisco de Holanda, Guimarães/Portugal, v.19, p. 91-102, 2012.

VILAÇA, TERESA. A educação em sexualidade na escola como uma vivência de cidadania: alunos e alunas como agentes socializadores da promoção de sexualidades saudáveis. In: MAGALHÃES, JOANALIRA CORPES; RIBEIRO PAULA REGINA COSTA (Org.), Educação para a Sexualidade. Rio Grande: Editora da FURG, 2014. p. 143-175.

VILAÇA, TERESA; SEQUEIRA, MANUEL; JENSEN, BJARNE BRUUN. Partnerships between teachers and the community: In-service training on the development of participatory and action-oriented sexual education in schools. Revista Doxa, Alicante/Espanha, v.15, n.1, p. 8596, 2011.

VILAÇA, TERESA; JENSEN, BJARNE BRUUN (2009). Potentials of Action-Oriented Sex Education Projects in the Development of Action Competence. In: BUIJS, GOOF; JOCIUTE, ALDONA; PAULUS, PETER; SIMOVSKA, VENKA (Eds.). Better Schools Through Health: Learning from Practice. Vilnius: NIGZ, State Environmental Health Centre of Lithuania, 2009. p. 89-91.

VILAÇA, TERESA; JENSEN, BJARNE BRUUN. Applying the S-IVAC Methodology in Schools to Explore Students' creativity to solve sexual health problems. In: MONTANÉ, MIREIA; SALAZAR, JOANA (Ed.). ATEE 2009 Annual Conference Proceedings. Brussels: ATEE, 2010. p. 215-227.

Universidade do Estado de Santa Catarina - UDESC Programa de Pós-Graduação em Educação - PPGE Revista Linhas Volume 17 - Número 34 - Ano 2016 revistalinhas@gmail.com 